\title{
Delegation of Authority as an Optimal (In)Complete Contract
}

\author{
by
}

ANDREAS ROIDER*

\begin{abstract}
This paper contributes to the literature on the foundations of incomplete contracts. In a holdup framework, we provide two sets of conditions under which simple delegation of authority is the solution to the complete-contracting problem. In cases where overinvestment can be ruled out, delegation is optimal if the payoffs of the parties satisfy certain separability conditions. If overinvestment might be an issue, delegation (possibly with restricted competencies) is optimal if additionally some continuity requirements are met. The paper also contributes to the literature on delegation, where such replication results have previously been derived in settings with asymmetric information. (JEL: D 82, D 23, L 14, L 22)
\end{abstract}

\section{Introduction}

Motivation. Contracts are often less complex than one might expect. It has long been recognized that in many instances contracts are vague or silent on a number of key features. Frequently, parties to a business transaction just allocate ownership or decisions rights between each other and do not resort to more detailed contracts (see, e.g., MACAULAY [1963]). In an attempt to explain these observations, the literature on the foundations of incomplete contracts has unearthed conditions under which such apparent contractual incompleteness arises as an equilibrium phenomenon. That is, it has been shown that, even if decisions are contractible and message games are feasible, simple contractual forms might be optimal. In particular, the complete lack of an ex ante contract (see, e.g., CHE AND HAUSCH [1999], HART AND MOORE [1999], SEGAL [1999]), noncontingent contracts specifying fixed decisions and payments (see, e.g., EdLIN AND REICHELSTEIN [1996], SEGAL AND Whinston

* I am grateful to Peter Eso, Gerd Mühlheusser, Georg Nöldeke, Stefan Reichelstein, Patrick Schmitz, Urs Schweizer, two referees, and seminar participants at Bern, the EEA meetings 2003 in Stockholm, the NAES meetings 2003 in Evanston, the GEABA meetings 2003 in Frankfurt, and the IIOC meetings 2004 in Chicago for very helpful comments and suggestions. I would like to thank the German Research Foundation (DFG) for financial support through Graduiertenkolleg "Quantitative Economics," SFB/TR15 "Governance and the Efficiency of Economic Systems," and a research fellowship. The hospitality of Stanford Graduate School of Business, where part of this research was conducted, is gratefully acknowledged. 
[2002]), or simple option contracts (see, e.g., NÖLDEKE AND SCHMIDT [1995], [1998], EdLin ANd Hermalin [2000], SchweIzer [2000]) might turn out to be solutions to a complete-contracting problem. Somewhat surprisingly, another institutional arrangement that is frequently observed in practice, namely simple delegation of authority, has only received limited attention in the literature on the foundations of incomplete contracts. The present paper represents a step in filling this gap.

Framework. In line with most of the literature on the foundations of incomplete contracts, we study a complete-contracting version of a holdup model. There are two symmetrically informed, risk-neutral parties who want to conduct a joint project. Ex ante one of the parties may make an observable, but nonverifiable investment to raise the value of an asset (the investor's human capital, a machine, etc.), which the parties use in the course of their project. We consider a setting where both parties directly profit from an increase in asset value. For example, $A$ 's investment might raise the value of a physical asset (a machine, a brand name, a customer list, etc.) from which both parties may profit. Likewise, a human-capital investment by an agent will frequently increase both the payoff of the principal and the agent's outside opportunities. ${ }^{1}$ Ex post, after uncertainty over the state of the world has been lifted, some decisions (for example, regarding the use of the asset) have to be taken. As in the literature on the foundations of incomplete contracts, we assume that the ex post decisions, transfer payments, and messages sent between the parties are verifiable by a court. Hence, these variables can be part of an initial contract. As the parties are symmetrically informed, they will always renegotiate the initial contract to an ex post efficient outcome after the ex post state of the world has been realized. Consequently, the purpose of the initial contract is to influence the threatpoint payoffs of the parties in a way that provides optimal investment incentives.

Intuition and Results. Below we derive conditions on the basics of the model (i.e., the payoff functions of the parties) under which an optimal contract amounts to nothing more than granting the investing party authority over the decisions and specifying a fixed transfer payment (e.g., a fixed wage). Our results are robust in the sense that they do not depend on the distribution of bargaining power between the parties and hold independently of the probability distribution of the random state of the world. Given that potentially more sophisticated message-dependent contracts are feasible, why might simple delegation of authority be optimal? First, note that applying results of MASKIN AND MOORE [1999] allows one to derive an upper bound for the

${ }^{1}$ Hence, in the terminology of CHE AND HAUSCH [1999], the investment will have both selfish and cooperative effects. Such hybrid investments have previously been considered by, e.g., Bernheim AND Whinston [1998], ChE AND HaUsCH [1999], SEgAL AND WHINSTON [2002], and ROIDER [2004]. If the investment affects the threatpoint payoff of only one of the parties, then, given some technical assumptions, a noncontingent contract specifying fixed decisions and payments will be optimal (see, e.g., SEgal AND Whinston [2002]). 
investment return under any contract. Second, suppose the investing party (i.e., the agent) is granted authority. Intuitively, if the agent has authority, ex post, he prefers decisions that maximize his total payoff. From an ex ante perspective, however, these decisions might fail to maximize the agent's marginal return from investing - thereby possibly leading to a lower net surplus than what the parties could possibly attain under some alternative contract. Below, however, we provide a simple sufficient condition on the payoff functions of the parties under which this issue does not arise. In this case, the agent's ex ante and ex post incentives with respect to the choice of decision are aligned, and delegation of authority to the agent attains the above-described upper bound on investment incentives. In particular, independent of the distribution of bargaining power between the parties and independent of the probability distribution of the random state of the world, this is the case if the decision-dependent parts of the threatpoint payoffs of the parties are proportional to the asset value (and if decisions have no additional investment-independent effects). Hence, in settings where it is optimal to maximize the agent's investment incentives, delegation of authority to the agent is optimal if the above condition is met.

In cases where potential overinvestment is an issue, we show that delegation of authority remains optimal if additionally some continuity requirements are met. However, in order to avoid overinvestment, it might be necessary to tailor competencies (in the sense that it might be necessary to contractually restrict discretion to a subset of possible decisions). Intuitively, specifying a choice set that rules out some actions dampens the agent's investment incentives, and by tailoring the agent's competencies in the right way it is possible to achieve the first best.

Contribution and Relation to the Literature. The paper is related to two strands of the literature. First, the paper contributes to the literature on the foundations of incomplete contracts. The basic structure of our model is the same as in SEGAL AND Whinston [2002]. ${ }^{2}$ They show that if it does not depend on the realization of the ex post state of the world which of the parties profits most from an investment, the parties can optimally restrict themselves to noncontingent contracts (i.e., contracts where the specified decisions and payments do not depend on messages sent by the parties). For example, SEGAL AND WHINSTON's [2002] result applies if investments have either purely selfish or purely cooperative effects (see, e.g., EDLIN AND REICHELSTEIN [1996] and CHE AND HAUSCH [1999], respectively). However, if both parties directly benefit from investments, SEGAL AND WHINSTON's [2002] result will frequently fail to hold. Consequently, our main focus is on such settings

${ }^{2}$ In slightly different holdup models HART AND Moore [1999] and SEgAL [1999] show that the complete absence of an ex ante contract might be optimal. In contrast to CHE AND HAUSCH [1999], they provide such results for the case of purely selfish investments. They consider settings where the parties want to trade one unit of a widget out of a large number of ex ante possible widgets. Only one special widget (where it is ex ante unknown which of the widgets is special) creates a surplus ex post. It is shown that if the complexity of the environment (i.e., the number of ex ante possible widgets) goes to infinity, the lack of a contract is optimal. For alternative explanations of the complete absence of a contract, see, e.g., TIROLE [1999]. 
(i.e., settings where optimal contracts are necessarily message-dependent), and we describe circumstances under which the optimal message-dependent contract takes the particularly simple form of delegation of authority to one of the parties.

Previous work on the optimality of simple forms of contingent contracts has mainly focused on option contracts, i.e., contracts where the specified decisions and payments are functions of messages of only one of the parties (see, e.g., SEgal And Whinston [2002]). ${ }^{3}$ However, as both decisions and payments are message-dependent, such option contracts might still take a rather complicated form. In a framework similar to SEGAL AND WHINSTON [2002], SCHWEIZER [2000] shows that if only one of the parties invests, simpler dichotomous option contracts (where one of the parties can select between just two decision-payment pairs) may be optimal if for any decision the net expected postrenegotiation payoff of the investing party is a strictly single-peaked function of the investment. However, in general it will depend on the probability distribution of the random state and on the distribution of bargaining power whether this condition is satisfied. Dichotomous option contracts may also be optimal if parties invest sequentially (see, e.g., NÖLDEKE AND SCHMidT [1995], [1998], EdLIN AND HERMALIN [2000]). Finally, there exist complete-contracting justifications of AGHION AND TIROLE's [1997] delegation model. However, their model differs from the present paper on a number of dimensions (e.g., they consider a moral-hazard problem of information acquisition). TIROLE [1999] shows that in AGHION AND TIROLE's [1997] setup some form of delegation might be optimal even if the ex post information structure is verifiable. In an earlier discussion-paper version of their paper, AGHION AND TIROLE [1997] show that, as long as the payoff consequences of decisions are ex ante unknown to both parties and as long as the agent is unresponsive to monetary incentives, forms of delegation may be optimal even if decisions are contractible ex ante.

Note that, throughout the paper, we focus on delegation of formal authority, which AGHion AND TiRole [1997] define as the legal right to take certain decisions. In their model a party without formal authority has, however, real authority if its recommendations are rubber-stamped. In holdup models the allocation of real authority is not an issue because the parties will always renegotiate to an ex post efficient outcome. Hence, we do not study second-best decision-making by a party with real authority, but explore whether the allocation of formal authority might generate optimal investment incentives from an ex ante perspective.

Second, the paper is related to the literature on delegation. This literature has mainly followed one of two approaches. As the revelation principle implies that, given some assumptions, centralized control cannot be dominated by any delegation arrangement (see, e.g., MYERSON [1982]), ${ }^{4}$ a first strand of the delegation litera-

${ }^{3}$ In this sense, delegation is a simple form of an option contract, and noncontingent contracts are a special case of delegation with restricted competencies. As a consequence, whenever noncontingent contracts are optimal, some form of delegation will be optimal as well.

4 Under centralized control the principal, based on agents' messages, selects decisions and payments from a contractually specified menu. 
ture has assumed that there are imperfections in the contracting environment that render the revelation principle invalid. For example, it has been shown that if there are limits to communication or commitment, if it is costly to process information, or if agents might collude, delegation of authority may be strictly optimal (for an overview, see, e.g., PoITEvin [2000], MoOKhERJEe [2003]). ${ }^{5}$ The present paper differs from this strand of the delegation literature by abstracting from such imperfections. Thereby, it follows the same approach as the second strand of the delegation literature that has aimed to derive replication results (i.e., conditions under which simple delegation of authority performs just as well as the best message-dependent contract). Replication results have previously been derived in adverse-selection models (see, e.g., MELUMAD, MoOKHERJEE, AND REICHELSTEIN [1992], [1995], MCAFEE AND MCMILlAN [1995], MOOKHERJEE AND REICHELSTEIN [1997], [2001], BALIGA AND SJÖSTRÖM [2001]) and multiagent moral-hazard problems (see, e.g., BALIGA AND SJÖSTRÖM [1998]). The present paper contributes to this strand of the delegation literature by providing a replication result in a symmetricinformation holdup model. To summarize: first, as in the literature on the foundations of incomplete contracts, we consider a complete-contracting version of a holdup problem. We contribute to this literature by providing conditions under which simple delegation of authority is optimal. Second, we contribute to the literature on delegation by obtaining a replication result in a model framework that has not been considered in this literature.

The remainder of the paper is structured as follows. In section 2 the model is introduced. In section 3 we present conditions for the optimality of delegation. There, we employ two illustrative examples related to the question of market entry to convey the intuition behind our results. Section 4 concludes. All proofs are relegated to an appendix.

\section{The Model}

\subsection{Description of the Model}

Basic Structure. We consider a standard holdup model with two risk-neutral, symmetrically informed parties, $P$ and $A$, who want to conduct a joint project. The principal $P$ has to rely on the agent $A$, who may make a preparatory investment $i \in[0, \bar{l}]$ that increases the value of an asset. For example, $A$ may invest in his human capital to perform better in later tasks. Alternatively, $A$ might possess some special skills that allow him to raise the value of a physical asset. After the investment has been made, the project is carried out. That is, some decisions $d=\left(d^{1}, \ldots, d^{n}\right) \in D$ have to be taken, where $D=D^{1} \times \cdots \times D^{n} \subset \Re^{n}$ and $n \geq 1$. While the investment

5 See also the recent literature on partial contracting, which allows for messagedependent mechanisms but assumes that only control over decisions (i.e., who has the right to take them), not the decisions themselves, is contractible (see, e.g., AGHION, DEWATRIPONT, AND REY [2002]). 
has to be made by $A$, we assume that both $P$ and $A$ are, in principle, able to take the decisions. Suppose that initially the principal $P$ holds the decision rights. Figure 1 depicts the sequence of events.

Figure 1

The Sequence of Events

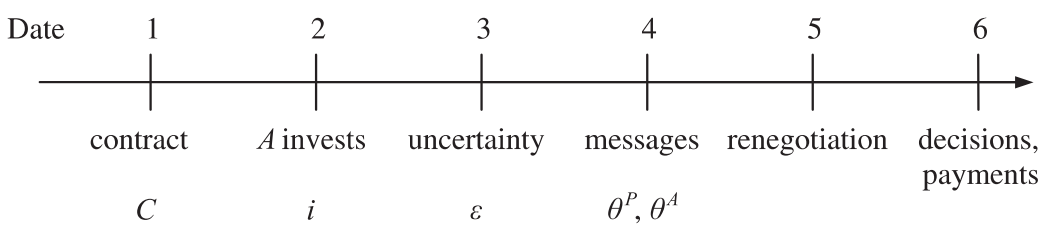

At date 1 , the parties sign a contract $\mathscr{C}$. Initial contracts are discussed in more detail below. At date 2, $A$ invests $i \in[0, \bar{\imath}]$ at $\operatorname{costs} c(i)$. At date 3 , uncertainty $\epsilon \in \mathscr{E}$ over the ex post state of the world $(i, \epsilon)$ is resolved, where $\mathscr{E}$ denotes the set of possible random states. A's investment increases the value $a(i, \epsilon)$ of the asset. We assume that $c$ and $a$ are continuously differentiable in $i$, and $a \geq 0, a_{i}>0, a_{i i}<0$, $c_{i}>0, c_{i i} \geq 0$, where, throughout, subscripts denote partial derivatives. As the $e x$ post state of the world is now known to both parties, at date $4 P$ and $A$ simultaneously send messages $\theta^{P}$ and $\theta^{A}$, respectively, about the ex post state of the world, where $\theta^{P}, \theta^{A} \in \Theta \equiv[0, \bar{\imath}] \times \mathscr{E}$. Finally, before decisions are taken and payments are made at date 6 , the parties may renegotiate the contract $\mathscr{C}$ at date 5 .

Information and Contracts. In line with the literature on the foundations of incomplete contracts, we assume that (i) all variables are observable to the parties, (ii) initial contracts cannot directly condition on the ex post state of the world $(i, \epsilon)$, and (iii) the decisions $d$, transfer payments between the parties, and messages sent at date 4 are verifiable by a court (and hence can be part of an initial contract). ${ }^{6}$ MASKIN AND MOORE [1999] have shown that in the present holdup setting with renegotiation the revelation principle allows one to restrict attention to direct revelation mechanisms (i) that specify the decisions and an ex post transfer payment from $P$ to $A$ as functions of the messages of the parties about the ex post state of the world, and (ii) under which truthful reporting of the ex post state by both parties is a Nash equilibrium on and off the equilibrium path. ${ }^{7}$ Formally, a contract $\mathscr{C}$ is defined as a mapping $\left[\widehat{d}, \widehat{t}^{P}, \widehat{t}^{A}\right]: \Theta \times \Theta \rightarrow D \times \Re \times \Re$, where $\widehat{t}^{P}\left(\theta^{P}, \theta^{A}\right)+\widehat{t}^{A}\left(\theta^{P}, \theta^{A}\right)=0$ for all $\theta^{P}$ and $\theta^{A}$.

${ }^{6}$ It would be straightforward to extend the model to the case that some of the decisions are not contractible ex ante.

7 Note that given our assumptions, there will exist ex ante transfer payments that ensure participation by both parties. As such ex ante payments have no effect on investment incentives, they are not considered explicitly. 
Payoffs. By sending messages $\theta^{P}$ and $\theta^{A}$ at date 4, the parties select decisions $\widehat{d}\left(\theta^{P}, \theta^{A}\right)$ and payments $\widehat{t}^{j}\left(\theta^{P}, \theta^{A}\right)$ for $j=P, A$ from the contractually specified menu. For the moment, we neglect the arguments of the functions $\widehat{d}$ and $\widehat{t}^{j}$ for ease of notation. If renegotiation of the contract at date 5 would fail, the parties would realize their threatpoint payoffs at date 6 . The threatpoint payoffs of $P$ and $A$ depend on the initial contract $\mathscr{C}$. They are given by $\pi^{j}(\widehat{d}, a(i, \epsilon), \epsilon)+\widehat{t}^{j}$ for $j=P, A$, where $\pi^{j}$ is assumed to be continuously differentiable in $i$ for $j=P, A$. Hence, as discussed above, the threatpoint payoffs of both parties may depend on the value of the asset. As the parties are symmetrically informed, they will, however, always succeed in renegotiating the initial contract and take ex post efficient decisions at date 6 . Thereby, they create an ex post surplus given by

$$
\phi(i, \epsilon) \equiv \max _{d \in D}\left\{\sum_{j} \pi^{j}(d, a(i, \epsilon), \epsilon)\right\},
$$

where we assume that $\phi(i, \epsilon)$ is nonnegative and continuously differentiable in $i$, $\phi_{i}>0$, and $\phi_{i i}<0$. Again in line with the literature, we assume that $P$ and $A$ share the resulting renegotiation surplus in Nash bargaining with exogenously given bargaining powers $\beta^{j}$, where $0<\beta^{j}<1$ for $j=P$, A. Hence, the postrenegotiation payoffs of $P$ and $A$ consist of their respective threatpoint payoffs and shares of the renegotiation surplus. They are given by

$$
\Pi^{j}\left(\widehat{d}, \widehat{t}^{j}, i, \epsilon\right) \equiv \underbrace{\left[\pi^{j}+\widehat{t}^{j}\right]}_{\text {threatpoint payoff }}+\beta^{j} \cdot \underbrace{\left[\phi-\pi^{P}-\pi^{A}\right]}_{\text {renegotiation surplus }}
$$

for $j=P, A$, where the arguments of the functions $\pi^{j}, \widehat{t}^{j}$, and $\phi$ have been dropped for ease of notation.

Optimal Contracts. As ex post efficiency is achieved through renegotiation, the purpose of the initial contract $\mathscr{C}$ is to generate investment incentives. The initial contract affects $A$ 's investment incentives because it influences the threatpoint payoffs of the parties and hence the distribution of the ex post surplus. As the parties are symmetrically informed, ex ante they sign a contract that maximizes the net expected surplus of their relationship. Define $\theta \equiv(i, \epsilon), \widehat{\Pi}^{j}\left(\theta^{P}, \theta^{A}, \theta\right) \equiv$ $\Pi^{j}\left(\widehat{d}\left(\theta^{P}, \theta^{A}\right), \widehat{t}^{j}\left(\theta^{P}, \theta^{A}\right), i, \epsilon\right)$, and $\bar{\Pi}^{j}(\theta) \equiv \widehat{\Pi}^{j}(\theta, \theta, \theta)$ for $j=P$, A. Formally, an optimal contract $\mathscr{C}^{*}$ solves the following problem:

$$
\max _{\left[\widehat{d}(\cdot), \hat{t}^{P}(\cdot), \hat{t}^{A}(\cdot)\right]}\{E[\phi(i, \epsilon)]-c(i)\},
$$

subject to the truth-telling constraints

$$
\bar{\Pi}^{P}(\theta) \geq \widehat{\Pi}^{P}\left(\theta^{P}, \theta, \theta\right) \quad \forall \theta, \theta^{P}
$$

and

$$
\bar{\Pi}^{A}(\theta) \geq \widehat{\Pi}^{A}\left(\theta, \theta^{A}, \theta\right) \quad \forall \theta, \theta^{A}
$$

of $P$ and $A$, respectively, and subject to the constraint

$$
i \in \underset{\widehat{i}}{\arg \max }\left\{E\left[\bar{\Pi}^{A}(\widehat{i}, \epsilon)\right]-c(\widehat{i})\right\} .
$$


Denote the investment that obtains under an optimal contract by $i\left(\mathscr{C}^{*}\right)$.

First Best. Ex ante efficiency (i.e., the first-best outcome) is achieved if the optimal contract induces an investment $i^{*}$ that maximizes the ex ante expected net surplus of the relationship. Formally,

$$
i^{*}=\underset{i}{\arg \max }\{E[\phi(i, \epsilon)]-c(i)\},
$$

where we assume $i^{*}>0$.

\subsection{Illustrative Examples}

In the following, we introduce two illustrative examples in order to provide an intuition for our findings. Consider a problem of project choice in the spirit of Aghion And TiRole [1997]. Suppose there are $n$ possible projects that $P$ and $A$ might pursue. After the agent has invested and the ex post state of the world has been realized, a decision has to be made which (if any) of the $n$ projects should be conducted (i.e., $\left.d=\left(d^{1}, \ldots, d^{n}\right) \in\{0,1\}^{n}\right)$. We simplify this setting of project choice in that we assume that (i) there is only one potential project (i.e., $n=1$ ), (ii) the asset value is identical to the investment (i.e., $a(i, \epsilon) \equiv i$ for all $\epsilon$ ), and (iii) the parties have identical bargaining power (i.e., $\beta^{j}=0.5$ for $j=P, A$ ). While this structure lends itself to various interpretations, both of the following examples are concerned with the question of market entry.

EXAMPLE 1 Suppose a principal has hired an agent to develop a new service or product, where $P$ 's valuation of the product is given by $i$. Ex post a decision has to be made about whether the parties should or should not enter the market with the newly developed product. If no market entry occurs (i.e., if $d=0$ ), the threatpoint payoffs of both parties are zero. If, however, entry occurs (i.e., if $d=1$ ), $P$ sells the product on the market. Thereby, $P$ derives a threatpoint payoff of $i$. Market entry also affects the agent $A$. Suppose that $A$ cares about the market's (possibly noisy) perception of him being a good innovator, where we assume that $A$ 's reputation is proportional to the value of the product and given by $(1+\epsilon) \cdot i$, where $\epsilon \in[-1,1]$.

The second example looks at decision-making in a joint venture.

EXAMPLE 2 Suppose that $P$ and $A$ are partners in a joint venture, where the parties contemplate market entry with a product developed by $A$. As above, the threatpoint payoffs of $P$ and $A$ are zero if there is no market entry. If, however, the parties enter the market, then each partner sells the product through its own outlets, and we let $i$ denote the profit per unit sold by either of the partners. Suppose that $P$ and $A$ face stochastic market demands $p(\epsilon)$ and $\alpha(\epsilon)$, respectively, where $p, \alpha>0$. For example, suppose that random fractions of consumers arrive at either partner's outlets.

What kind of contracts should the parties sign in the above examples? Might it suffice to sign a noncontingent contract specifying that the parties enter the market 
no matter what? Why might such contracts fail to be optimal? If this is the case, does simple delegation of authority lead to the desired outcome, or are more elaborate contracts necessary? These questions are the focus of the next section.

\section{Delegation of Authority}

In this section we present conditions for the optimality of delegation that do not depend on the distribution of bargaining power between the parties and that do not depend on the probability distribution of the random state of the world.

DEFINITION 1 We speak of delegation of authority to the agent if the initial contract specifies some fixed payment $\widehat{t}^{A} \in \Re$ and prescribes that party $A$ is free to choose any $\widehat{d} \in D$.

DEFINITION 2 Under delegation of authority, we speak of restricted competencies if party $A$ is free to choose any $\widehat{d} \in D^{*}$, where $D^{*} \subset D$.

Given our assumption that decisions are contractible, the above-described transfer of authority to the agent through an explicit delegation contract is always feasible. Alternatively, it might also be possible to transfer authority to the agent by letting him acquire ownership of some (nonhuman) assets. For example, suppose there is a machine (initially owned by $P$ ), and all decisions in $D$ relate to how this machine should be used. If, in the initial contract, the parties just agree to transfer ownership of this asset to the agent in exchange for some fixed payment, this will lead to the same outcome as delegation of authority: following the definition in the property-rights theory of the firm (see, e.g., GROSSMAN AND HART [1986], HART AND MOORE [1990], HART [1995]), ownership of an asset confers residual rights of control over the asset on the owner, i.e., if not bound contractually, he has authority to decide on the asset's uses. ${ }^{8}$

There might, however, be two problems with such a transfer of authority through asset ownership. First, the project that $P$ and $A$ aim to conduct might not necessarily require a physical (i.e., nonhuman) asset. ${ }^{9}$ For example, consider the case that $P$ and $A$ aim to provide a service, and the only asset on which they rely is their respective human capital. As, in this case, there is no asset of which ownership could be transferred, the above-discussed allocation of decision rights through a transfer of ownership is not feasible. Second, more generally, even if physical assets are involved, ownership of these assets (e.g., the machines) might not imply authority over all decisions relevant for the project. Importantly, note that, in

8 In this respect, our results also contribute to the literature on the foundations of the property-rights theory of the firm (see, e.g., CHE AND HAUSCH [1999], MASKIN AND TIROLE [1999], ROIDER [2004]). This literature provides conditions under which the restriction of attention to allocations of ownership rights as made in the propertyrights theory is justified even when quantity (trade) contracts are feasible.

9 For a more detailed discussion of such settings, see, e.g., RAJAN AND ZINGALES [1998]. 
accordance with the holdup literature, we assume that the payoffs of the parties are not verifiable (and consequently not contractible). Hence, in contrast to the principal-agent literature, where "selling the shop" is generally meant to imply a transfer of all payoff rights to the agent (thereby making him residual claimant), such a transfer of payoff rights is not possible here. Instead, in the property-rights theory, a firm is defined as a collection of nonhuman assets. Hence, even if $A$ "buys the firm," he only acquires residual rights of control over the relevant assets, and does not necessarily acquire control over all decisions relevant to the project. $^{10}$

Formally, suppose there is a set of (nonhuman) assets $S \equiv\left\{S^{1}, \ldots, S^{m}\right\}$, where $m \geq 1$, of which ownership can in principle be transferred. If there exists a subset $S^{D} \subseteq S$ such that ownership of $S^{D}$ (i.e., residual rights of control over the assets in $S^{D}$ ) implies authority over all decisions in $D$, then the outcome under delegation of authority (as defined above) can be replicated through a transfer of asset ownership.

In order to identify conditions under which delegation of authority performs just as well as the best message-dependent contract, we will proceed in two steps. First, note that, as the parties will always renegotiate to an ex post efficient outcome at date 5 , at date 4 when sending their messages $P$ and $A$ play a constant-sum game (where the constant sum is given by $\phi(i, \epsilon)$ ). This observation, in combination with the truth-telling constraints (4) and (5), allows us to derive an upper bound for A's marginal investment return under any arbitrary contract (see, e.g., MASKIN AND MOORE [1999]). Second, we identify a condition on the payoff functions of the parties that ensures that simple delegation of authority to $A$ attains this upper bound. Hence, in settings where maximum investment incentives are desirable, delegation of authority is optimal if Condition 1 below holds. This case is discussed in section 3.1. If overinvestment cannot be ruled out from the outset, we show that delegation (possibly in combination with carefully restricted competencies) is optimal if additionally some continuity requirements are met. This case is discussed in section 3.2.

\subsection{Underinvestment Case}

For the moment, suppose that even under the optimal contract the equilibrium investment level $i\left(\mathscr{C}^{*}\right)$ falls short of the first-best investment level $i^{*}\left(i . e ., i\left(\mathscr{C}^{*}\right) \leq i^{*}\right)$. At the end of this subsection, we provide simple conditions under which this will indeed hold true. In such underinvestment settings, delegation of authority to $A$ is optimal if and only if it leads to an investment level weakly above the equilibrium investment under any other feasible contract.

Under which circumstances will this be the case? To illustrate the underlying intuition consider Example 1. For the moment we restrict attention to message-

${ }^{10}$ For a more extensive discussion of the relationship between the principal-agent and property-rights theories, see, e.g., HART [1995]; for a critical assessment of the property-rights theory, see, e.g., HOLMSTROM AND ROBERTS [1998]. 
independent decisions and payments. In Example 1, market entry is always ex post efficient (because $i(2+\epsilon) \geq 0$ for all $i$ and $\epsilon$ ), and hence the ex post surplus is given by $\phi(i, \epsilon)=i(2+\epsilon)$. Consequently, it follows from (2) that the postrenegotiation payoff of $A$ is given by

$$
\Pi^{A}\left(\widehat{d}, \widehat{t}^{A}, i, \epsilon\right)= \begin{cases}i(1+0.5 \epsilon)+\widehat{t}^{A} & \text { if } \widehat{d}=0, \\ i(1+\epsilon)+\widehat{t}^{A} & \text { if } \widehat{d}=1 .\end{cases}
$$

If the initial contract is silent with respect to market entry, the parties will agree on market entry ex post, and $A$ appropriates half of the ex post surplus through such renegotiation. If the initial contract already prescribes (ex post efficient) market entry, there will be no renegotiation, and $A$ just obtains his threatpoint payoff. For all $i$ and $\epsilon$ define

$$
\widetilde{d}^{A}(i, \epsilon) \in \underset{\widehat{d} \in D}{\arg \max }\left\{\Pi_{i}^{A}\left(\widehat{d}, \widehat{t}^{A}, i, \epsilon\right)\right\} .
$$

It follows from (8) that we have $\widetilde{d}^{A}(i, \epsilon)=0$ if $\epsilon<0$, and $\widetilde{d}^{A}(i, \epsilon)=1$ if $\epsilon \geq 0$. That is, it depends on the realization of the random state of the world which contractually specified decisions maximize the agent's investment incentives. Only in ex post states where the agent's investment has a sufficiently strong effect on his reputation (i.e., where $\epsilon \geq 0$ ) does contractually prescribed market entry lead to maximal investment returns. In states where the agent's reputation is relatively unresponsive to his investment (i.e., where $\epsilon<0$ ), the agent would derive higher investment returns if the initial contract specified that the question of market entry is only decided in ex post negotiation (i.e., $\widehat{d}=0$ ). Note that even if (incentive-maximizing) decisions $\widetilde{d}^{A}(i, \epsilon)$ were taken in every ex post state, the agent's private investment return would fall short of the social investment return $\phi_{i}(i, \epsilon)$ because $2+\epsilon>\max \{1+\epsilon, 1+0.5 \epsilon\}$ for all $\epsilon$. As a consequence, the parties face an underinvestment problem, and it will be optimal to maximize $A$ 's investment incentives. ${ }^{11}$

Now, does there exist a contract that leads to decisions $\widetilde{d}^{A}(i, \epsilon)$ ? In particular, might delegation of authority to the agent achieve this? Suppose that $A$ indeed has authority. In this case, $A$ makes decisions that maximize his total postrenegotiation payoff:

$$
\widehat{d}^{A}(i, \epsilon) \in \arg \max _{\widehat{d} \in D} \Pi^{A}\left(\widehat{d}, \widehat{t}^{A}, i, \epsilon\right) .
$$

It immediately follows from (8), (9), and (10) that in Example 1 we have $\widehat{d}^{A}(i, \epsilon)=$ $\widetilde{d}^{A}(i, \epsilon)$ for all $i$ and $\epsilon .{ }^{12}$ Hence, in the context of Example 1, delegation of authority to the agent will be optimal (see Proposition 1 below). A completely analogous

11 This observation immediately implies that in the present example noncontingent contracts, which specify fixed decisions and payments, lead to less than maximal investment incentives, and hence a noncontingent contract will not be optimal. More generally, Example 1 shows that if both parties profit from an investment and if the parties are relatively symmetric, SEGAL AND WHINSTON's [2002] condition for the optimality of noncontingent contracts is likely to be violated. This is illustrated in more detail in Appendix A.1.

12 We assume that decisions $\widetilde{d}^{A}(i, \epsilon)$ and $\widehat{d}^{A}(i, \epsilon)$ exist in every ex post state $(i, \epsilon)$. 
argument applies in Example 2. That is, despite the fact that in both of the above examples complicated contracts are feasible, a simple contractual arrangement is optimal: it suffices to grant party $A$ authority to decide over market entry and to agree on a fixed transfer payment. Intuitively, as the threatpoint payoffs of the parties are proportional to the asset value, the postrenegotiation payoffs of the parties are proportional to the asset value as well. This implies that in every ex post state $\Pi^{A}$ and $\Pi_{i}^{A}$ are maximized by the same decisions $\widehat{d}$.

If the following condition is met, this basic intuition extends to more general settings (e.g., settings where multidimensional decisions have to be taken or where the asset value is stochastic).

CONDITION 1 The decision-dependent parts of the threatpoint payoffs of the parties are linear in the asset value, and the decisions have no investment-independent effect. Formally, the threatpoint payoffs can be expressed as

$$
\pi^{j}(\widehat{d}, a(i, \epsilon), \epsilon) \equiv \rho^{j}(\widehat{d}, \epsilon) \cdot a(i, \epsilon)+\gamma^{j}(a(i, \epsilon), \epsilon),
$$

where $\gamma^{j}$ is continuously differentiable in $i$ for $j=P, A$.

In general, it depends not only on the shape of the functions $\pi^{P}$ and $\pi^{A}$, but also possibly on the distribution of bargaining power between the parties, whether the agent's ex post and ex ante incentives with respect to the choice of decision are aligned (to see this, reconsider the postrenegotiation payoff function (2) of the agent). As a consequence, it might depend on the distribution of bargaining power between the parties whether delegation is optimal. However, if Condition 1 is met, this issue does not arise. ${ }^{13}$ That is, Condition 1 constitutes an easily interpretable sufficient condition for the optimality of delegation that does not require knowledge of the bargaining power of the parties. ${ }^{14}$

PROpOSITION 1 (UNDERINVESTMENT CASE) If Condition 1 holds and the parties face an underinvestment problem, delegation of authority to A is optimal.

It now remains to discuss under which circumstances the parties indeed face an underinvestment problem. Define

$$
i^{D} \in \underset{i}{\arg \max }\left\{E\left[\Pi^{A}\left(\widetilde{d}^{A}(i, \epsilon), \widehat{t}^{A}, i, \epsilon\right)\right]-c(i)\right\},
$$

for $\widehat{t}^{A} \in \mathfrak{R}$. Clearly, if Condition 1 is satisfied, delegation is optimal as long as $i^{D} \leq i^{*}$ holds. While, in general, it depends on the probability distribution of $\epsilon$ whether this is the case, Lemma 1 below identifies properties of $P$ 's payoff function such that an underinvestment problem arises independent of the probability distribution of $\epsilon$.

13 For the two-sided investment case, EDLIN AND REICHELSTEIN [1996] derive a separability condition on the payoff functions of the parties under which they can optimally restrict themselves to noncontingent contracts. Their Condition A3 allows for investment-independent effects of decisions, but in contrast to our Condition 1 above, they only consider purely selfish investments. As a consequence, neither of the two conditions is a special case of the other.

14 In Appendix A.3 we extend Proposition 1 below to the case of a multidimensional investment by the agent. 
LEMMA 1 (UNDERINVESTMENT) If Condition 1 holds and $\rho^{P}, \gamma_{i}^{P} \geq 0$, the parties face an underinvestment problem.

Intuitively, if the investment has a direct positive effect on both parties, the agent's investment incentives are reduced (see, e.g., CHE AND HAUSCH [1999]). On the one hand, A's investment raises his own threatpoint payoff. This has a positive effect on $A$ 's investment incentives. On the other hand, however, $P$ 's threatpoint payoff goes up too. This harms investment incentives because the available renegotiation surplus is reduced. As a consequence, private investment returns fall short of social investment returns, and the first best cannot be attained.

\subsection{Overinvestment Case}

In this subsection, we turn to the case that overinvestment cannot be ruled out from the outset (i.e., by knowledge of the payoff functions of the parties). For example, suppose that in some ex post states $A$ 's preferred decisions are unfavorable for $P$ in the sense that they cause $P$ 's threatpoint payoff to be negative (i.e., $\rho^{P}\left(\widehat{d}^{A}(i, \epsilon), \epsilon\right)<0$ for some $(i, \epsilon))$. In this case, $A$ 's investment would affect $P$ 's threatpoint payoff negatively, thereby possibly providing $A$ with private investment returns above social investment returns. ${ }^{15}$ If such ex post states are sufficiently likely, allowing the agent to take any decision might lead to overinvestment. However, even when overinvestment cannot be ruled out from the outset, it is possible to state conditions for the optimality of delegation that do not depend on the probability distribution of $\epsilon$. In particular, delegation of authority turns out to be optimal if Condition 1 and some additional (arguably mild) requirements are met, but it might be necessary to contractually restrict the agent's competencies.

Condition 2 (i) Decisions are continuous (i.e., $D \equiv\left[0, \bar{d}^{1}\right] \times \cdots \times\left[0, \bar{d}^{n}\right]$ ). (ii) Decisions have continuous effects (i.e., $\rho^{j}(\widehat{d}, \epsilon)$ is continuous in $\widehat{d}$ for $\left.j=P, A\right)$. (iii) Null decisions exist (i.e., $\rho^{j}((0, \ldots, 0), \epsilon)=0$ for all $\epsilon$ and $\left.j=P, A\right)$.

Part (iii) of Condition 2 states that if no decisions are taken (i.e., if the status quo is maintained), the decision-dependent parts of the threatpoint payoffs are zero. Intuitively, if overinvestment might occur, it is possible to reduce $A$ 's investment incentives by specifying in the initial contract that ex post the agent may select only from some set $D^{*}$ of decisions, where $D^{*} \subset D$. In this case, incentive-maximizing decisions $\widetilde{d}^{A}(i, \epsilon)$ might not be feasible, which would result in lower returns from investing. Hence, by carefully choosing $D^{*}$ it might be possible to provide $A$ with first-best investment incentives. Conditions 1 and 2 jointly ensure that this is the case.

To illustrate this, suppose that allowing $A$ to choose from $D$ would lead to overinvestment. First, Conditions 1 and 2 imply that there exists some truncated

15 That is, there would be a rent-seeking motive for investment (see, e.g., RAJAN AND ZINGALES [1998]). 
choice set $D^{*} \subseteq D$ such that (given that $A$ is allowed to choose any $\widehat{d} \in D^{*}$ ex post), $i^{*}$ satisfies the first-order condition of $A$ 's ex ante maximization problem.

Second, note that given that the asset value affects the threatpoint payoffs of both parties, for given decisions the postrenegotiation payoff of $A$ might very well fail to be concave in his investment. This holds true even if $a, \pi^{P}, \pi^{A}$, and $\phi$ are well behaved. To see this note that (2) implies that for fixed decisions and payments the marginal investment return of $A$ in a given ex post state is given by $\beta^{P} \pi_{i}^{A}+\beta^{A} \phi_{i}-\beta^{A} \pi_{i}^{P}$. Hence, even if $\pi^{A}, \pi^{P}$, and $\phi$ are strictly concave in $i$, the investment return is not necessarily concave. However, if the agent has authority, his postrenegotiation payoff turns out to be concave in the investment if null decisions exist and $\gamma^{j}(a(i, \epsilon), \epsilon) \equiv \widetilde{\gamma}^{j}(\epsilon) \forall \epsilon$ holds for $j=P, A$ : intuitively, the existence of null decisions ensures that in every ex post state $A$ can secure himself a nonnegative investment return, which in combination with Condition 1 implies concavity.

Proposition 2 (OVERINVESTMENT CASE) If Conditions 1 and 2 hold, and $\gamma^{j}(a(i, \epsilon), \epsilon) \equiv \tilde{\gamma}^{j}(\epsilon)$ for all $\epsilon$ and $j=P, A$, delegation of authority to $A$ is optimal, but it might be necessary to restrict competencies.

In the proof of Proposition 2 we show that one simple way to optimally restrict competencies is to rule out extreme choices. ${ }^{16}$ That is, we show that a choice set of the form $D^{*}=\left[0, \bar{d}^{1}-\omega^{1}\right] \times \cdots \times\left[0, \bar{d}^{n}-\omega^{n}\right]$ for some $\omega^{1}, \ldots, \omega^{n} \geq 0$ is optimal.

Note that in the present overinvestment case it will in general not be possible to replicate the necessary fine tuning of decision rights through the rather coarse instrument of a transfer of asset ownership, where ownership of each individual asset might imply a whole set of decision rights.

\section{Conclusion}

The present paper contributes to two strands of the literature. First, the literature on the foundations of incomplete contracts has identified circumstances under which simple contractual arrangements (such as noncontingent contracts, options, or the complete lack of an initial contract) are solutions to a complete-contracting problem; thereby helping to explain why contracts frequently appear to be incomplete. We add to this literature by providing conditions under which simple delegation of authority is optimal even though complete contracts are feasible. Moreover, as an alternative to delegation, it may be possible to transfer authority

16 While in the present model restricting competencies serves to reduce investment incentives, SZALAY [2005] discusses a principal-agent model where restricting the agent to "extreme" decisions (i.e., decisions that may turn out to be either very beneficial or very detrimental) may foster the agent's incentives to acquire decisionrelevant information. Partial forms of delegation may also emerge if a principal can only commit to a decision rule, but not to monetary transfers (e.g., HolmSTROM [1984], Melumad and Shibano [1991], Armstrong [1994]). 
to the agent through a transfer of ownership rights. Hence, the paper also contributes to the literature on the foundations of the property-rights theory of the firm. Second, the literature on delegation has shown that in settings of asymmetric information delegation might perform just as well as the best message-dependent mechanism. The present paper contributes to this strand of the delegation literature by providing such a replication result in a symmetric-information holdup model.

Our conditions for the optimality of delegation are robust in the sense that they do not depend on the distribution of bargaining power between the parties or on the probability distribution of the random state of the world. First, if the parties face an underinvestment problem and Condition 1 holds, unrestricted delegation of authority to $A$ is optimal because it maximizes $A$ 's incentives to invest. Second, if overinvestment might occur, delegation is nevertheless optimal if, in addition to Condition 1, decisions are continuous and have a continuous effect, and null decisions exist. In the latter case it might be optimal to restrict competencies by allowing $A$ to choose from only a subset of the feasible decisions. To summarize, our results suggest that in settings (joint ventures, employment relationships, etc.) where increases in asset value (e.g., the value of a physical asset or the value of the agent's human capital) have proportional effects on the parties, some form of delegation of authority is optimal, and there is no need for the parties to resort to more complicated contracts.

So far we have considered a setting where one of the parties invests. If both parties invest simultaneously, SEGAL AND WHINSTON [2002] have shown that noncontingent contracts may be optimal if the decision-dependent parts of the payoffs of the parties only depend on a one-dimensional aggregate of investments. ${ }^{17}$ In a similar spirit, it is straightforward to extend our results to the case that both parties invest, but that the payoffs of the parties only depend on the total amount invested. For example, HART [1995] has argued that in the case of investments in physical capital it will frequently not matter which of the parties actually invests. Similarly, in marketing joint ventures or horizontal production joint ventures, partners will often provide homogeneous inputs (such as money or some intermediate product) such that only the total amount invested matters. ${ }^{18}$ Intuitively, in the case of transferable investments only one of the parties will invest in equilibrium (if some technical assumptions are met). As a consequence, the above results continue to hold, but it will depend on the parameters of the model whether authority should be delegated to party $A$ or party $P$. If invest-

17 Without imposing aggregation assumptions, EDLIN AND REICHELSTEIN [1996] and CHE AND HAUSCH [1999] prove such results for the case that both investments are purely selfish (i.e., only the respective investor benefits directly) and for the case that both investments are highly cooperative in every ex post state, respectively.

18 LAFFONT AND TIROLE [1993, p. 88] have argued that, due to "creative accounting" opportunities, even homogeneous inputs might be hard to verify. For example, if monetary contributions are used to buy certain inputs or services, the investor might collude with the provider of the input in order to overstate its price. 
ments cannot be aggregated in this way, optimal contracts have in general to provide investment incentives for both parties. It awaits future research to determine under which conditions some form of delegation of authority is optimal in such cases.

\section{Appendix}

\section{A.1 Noncontingent Contracts}

In the following, we briefly discuss SEGAL AND WHINSTON's [2002] result on the optimality of noncontingent contracts (see their Proposition 4). Consider a setting where $D=[0, \bar{d}]$, and $\pi_{i}^{A}, \pi_{i d}^{A}, \pi_{i}^{P}, \pi_{i d}^{P}>0$. In this case, it follows from equation (2) that the marginal effect of a change in $\widehat{d}$ on $A$ 's investment return is given by

$$
\Pi_{i d}^{A}(\cdot)=\beta^{A} \pi_{i d}^{A}(\cdot)-\beta^{P} \pi_{i d}^{P}(\cdot) .
$$

We say that the investment has a mainly selfish effect in ex post state $(i, \epsilon)$ if $\Pi_{i d}^{A}(i, \epsilon) \geq 0$, and that it has a mainly cooperative effect otherwise. Given some assumptions, SEGAL AND WHINSTON [2002] show that noncontingent contracts are optimal if it does not depend on the realization of uncertainty $\epsilon$ whether the investment has a mainly selfish or mainly cooperative effect on the investing party (see their Condition $H^{ \pm}$). This condition is, for example, satisfied if the investment is purely selfish, i.e., if $\pi_{i}^{A}>\pi_{i}^{P} \equiv 0$ (see EDLIN AND REICHELSTEIN [1996]), or if the investment is purely cooperative, i.e., if $\pi_{i}^{P}>\pi_{i}^{A} \equiv 0$ (see CHE AND HAUSCH [1999]). It follows from (A1) that, in general (i.e., if investments have both selfish and cooperative effects), it depends on the distribution of bargaining power between the parties and on the shape of the functions $\pi^{A}$ and $\pi^{P}$ whether SEGAL AND WHINSTON's [2002] condition is met. In particular, if the parties are sufficiently symmetric $\left(\right.$ e.g. , if $\beta^{P}=\beta^{A}=0.5$ and $\left.\pi^{A}(\cdot) \approx \pi^{P}(\cdot)\right)$, it is likely that this is not the case, and noncontingent contracts are in general not optimal.

\section{A.2 Proof of Proposition 1}

Note that when the parties send their messages at date 4, they play a constant-sum game, i.e.,

$$
\widehat{\Pi}^{P}\left(\theta^{P}, \theta^{A}, \theta\right)+\widehat{\Pi}^{A}\left(\theta^{P}, \theta^{A}, \theta\right)=\phi(\theta) \quad \text { for all } \theta^{P}, \theta^{A}, \theta \in \Theta .
$$

Combining (A2) and $P$ 's truth-telling constraint (4) implies

$$
\phi(\theta)-\bar{\Pi}^{A}(\theta)=\bar{\Pi}^{P}(\theta) \geq \widehat{\Pi}^{P}\left(\theta^{\prime}, \theta, \theta\right)=\phi(\theta)-\widehat{\Pi}^{A}\left(\theta^{\prime}, \theta, \theta\right)
$$

for all $\theta, \theta^{\prime} \in \Theta$,

and hence

$$
\bar{\Pi}^{A}(\theta) \leq \widehat{\Pi}^{A}\left(\theta^{\prime}, \theta, \theta\right) \quad \text { for all } \theta, \theta^{\prime} \in \Theta .
$$


Combining A's truth-telling constraint (5) and (A4) yields

$$
\widehat{\Pi}^{A}\left(\theta, \theta^{\prime}, \theta\right) \leq \bar{\Pi}^{A}(\theta) \leq \widehat{\Pi}^{A}\left(\theta^{\prime}, \theta, \theta\right) \quad \text { for all } \theta, \theta^{\prime} \in \Theta,
$$

and by analogy

$$
\widehat{\Pi}^{A}\left(\theta^{\prime}, \theta, \theta^{\prime}\right) \leq \bar{\Pi}^{A}\left(\theta^{\prime}\right) \leq \widehat{\Pi}^{A}\left(\theta, \theta^{\prime}, \theta^{\prime}\right) \quad \text { for all } \theta, \theta^{\prime} \in \Theta .
$$

Finally, combining the second inequality in (A5) and the first inequality in (A6) implies

$$
\bar{\Pi}^{A}(\theta)-\bar{\Pi}^{A}\left(\theta^{\prime}\right) \leq \widehat{\Pi}^{A}\left(\theta^{\prime}, \theta, \theta\right)-\widehat{\Pi}^{A}\left(\theta^{\prime}, \theta, \theta^{\prime}\right)
$$

for all $\theta, \theta^{\prime} \in \Theta$ (see, e.g., MASKIN AND MoORE [1999]). Hence, for any $\theta=(i, \epsilon)$ and $\theta^{\prime}=\left(i^{\prime}, \epsilon\right)$, where $i^{\prime}>i$, the inequality (A7) allows us to derive an upper bound to $A$ 's investment return: ${ }^{19}$

$$
\begin{aligned}
& \frac{\overline{\partial \bar{\Pi}^{A}(\theta)}}{\partial i} \equiv \limsup _{i^{\prime} \rightarrow i} \frac{\bar{\Pi}^{A}(\theta)-\bar{\Pi}^{A}\left(\theta^{\prime}\right)}{i-i^{\prime}} \\
& \leq \beta^{A} \phi_{i}(i, \epsilon) \\
& +\limsup _{i^{\prime} \rightarrow i}\left\{\beta^{P} \pi_{i}^{A}\left(\widehat{d}\left(\theta^{\prime}, \theta\right), a(i, \epsilon), \epsilon\right)-\beta^{A} \pi_{i}^{P}\left(\widehat{d}\left(\theta^{\prime}, \theta\right), a(i, \epsilon), \epsilon\right)\right\} \\
& =\beta^{A} \phi_{i}(i, \epsilon)+\left[\beta^{P} \gamma_{i}^{A}(a(i, \epsilon), \epsilon)-\beta^{A} \gamma_{i}^{P}(a(i, \epsilon), \epsilon)\right] \\
& +\limsup \left\{a_{i}(i, \epsilon) \cdot\left[\beta^{P} \rho^{A}\left(\widehat{d}\left(\theta^{\prime}, \theta\right), \epsilon\right)-\beta^{A} \rho^{P}\left(\widehat{d}\left(\theta^{\prime}, \theta\right), \epsilon\right)\right]\right\} \text {, } \\
& i^{\prime} \rightarrow i \\
& \leq \beta^{A} \phi_{i}(i, \epsilon)+\left[\beta^{P} \gamma_{i}^{A}(a(i, \epsilon), \epsilon)-\beta^{A} \gamma_{i}^{P}(a(i, \epsilon), \epsilon)\right] \\
& +a_{i}(i, \epsilon) \cdot\left[\beta^{P} \rho^{A}\left(\widehat{d}^{A}(i, \epsilon), \epsilon\right)-\beta^{A} \rho^{P}\left(\widehat{d}^{A}(i, \epsilon), \epsilon\right)\right],
\end{aligned}
$$

where the second inequality follows from (10) and Condition 1 . Note that Condition 1 implies that, while the incentive-maximizing decisions $\widehat{d}^{A}(i, \epsilon)$ may depend on the random state $\epsilon$, they do not vary with the level of $A$ 's investment. In this respect, Condition 1 is a polar case to SEgAL AND WHINSTON's [2002] Condition $H^{ \pm}$, which requires that, for a given $i$, the incentive-maximizing decisions be independent of the random state $\epsilon$. As the parties face an underinvestment problem, it is optimal to maximize $A$ 's investment incentives. Given the above inequality, this is achieved by specifying in the ex ante contract that $A$ receives some fixed payment $\widehat{t}^{A} \in \Re$ and that he is free to choose any $\widehat{d} \in D$ ex post.

\section{A.3 Extension: A Multidimensional Investment}

Frequently, an agent will engage in various preparatory activities. If investment components are strategic complements, Proposition $1 \mathrm{can}$ be extended to the case of a multidimensional investment. Under slight abuse of notation, suppose that $A$ chooses a $k$-dimensional investment vector $i \equiv\left(l^{1}, \ldots, l^{k}\right), k \geq 1$, from a compact subset of $\Re^{k}$. For simplicity, assume that investment costs are linear, i.e., $c(i)=$ $\iota^{1}+\cdots+\iota^{k}$. Now, suppose that authority over ex post decisions is delegated to $A$

${ }^{19}$ For a similar approach, see, e.g., CHE AND HAUSCH [1999]. 
and that he receives a fixed payment $\widehat{t}^{A} \in \Re$. In this case, define $\iota^{l}\left(l^{-l}\right)$ as the $l$ th investment component that $A$ chooses ex ante for a given $\iota^{-l}$. Formally,

$$
\iota^{l}\left(\iota^{-l}\right) \in \arg \max _{l^{l}}\left\{\Pi^{A}\left(\widehat{d}^{A}(i, \epsilon), \widehat{t}^{A}, i, \epsilon\right)-l^{l}\right\}
$$

for $l=1, \ldots, n$. If Condition 1 holds, null decisions exist, and $\gamma^{j}(a(i, \epsilon), \epsilon) \equiv \tilde{\gamma}^{j}(\epsilon)$ for all $i, \epsilon$ and $j=P, A$, then $\iota^{l}\left(l^{-l}\right)$ and the equilibrium investment vector $\widetilde{i}$ are unique. If, in addition, the investment components are strategic complements, then delegation is optimal because, for each investment component, it is optimal to maximize A's incentives. Figure A1 serves to illustrate Proposition 3.

Proposition 3 Suppose A makes a multidimensional investment and the parties face an underinvestment problem. If Conditions $1,2(i i i), \gamma^{j}(a(i, \epsilon), \epsilon) \equiv \widetilde{\gamma}^{j}(\epsilon) \forall i, \epsilon$, and $a_{l l_{l} m}, \phi_{l l_{l} m}>0$ hold for all $l \neq m$ and $j=P, A$, delegation of authority to $A$ is optimal.

Proof Condition 2(iii) implies that $\beta^{P} \cdot \rho^{A}\left(\widehat{d}^{A}(i, \epsilon), \epsilon\right)-\beta^{A} \cdot \rho^{P}\left(\widehat{d}^{A}(i, \epsilon), \epsilon\right) \geq 0$ $\forall i, \epsilon$. Hence, for all $l, \iota^{l}\left(l^{-l}\right)$ is unique and nondecreasing in $\iota^{-l}$. Moreover, given delegation, the equilibrium investment vector $\widetilde{i}=\left(\widetilde{\iota}^{l}, \widetilde{\iota}^{-l}\right)$ is unique (where $\tilde{i}$ is implicitly defined by $\iota^{l}\left(\widetilde{\iota}^{-l}\right)=\widetilde{\iota}^{l}$ for all $l$ ). Similarly to the proof of Proposition 1 , it follows from Condition 1 that under any arbitrary contract $\mathscr{C}$ it holds that

$$
\begin{aligned}
& \overline{\frac{\partial \bar{\Pi}^{A}(\theta)}{\partial l^{l}}} \leq \beta^{A} \cdot \phi_{l^{l}}(i, \epsilon)+a_{l} l(i, \epsilon) \cdot\left[\beta^{P} \cdot \rho^{A}\left(\widehat{d}^{A}(i, \epsilon), \epsilon\right)\right. \\
& \left.-\beta^{A} \cdot \rho^{P}\left(\widehat{d}^{A}(i, \epsilon), \epsilon\right)\right] \quad \forall i, \epsilon .
\end{aligned}
$$

Hence, for a given $\iota^{-l}$, the $l$ th investment component chosen when authority is delegated to $A$ is weakly larger than the $\iota^{l}$ chosen under any other contract $\mathscr{C}$. Define

Figure Al

Delegation and a Multidimensional Investment:

An Example Where $i \equiv\left(\iota^{1}, \iota^{2}\right)$

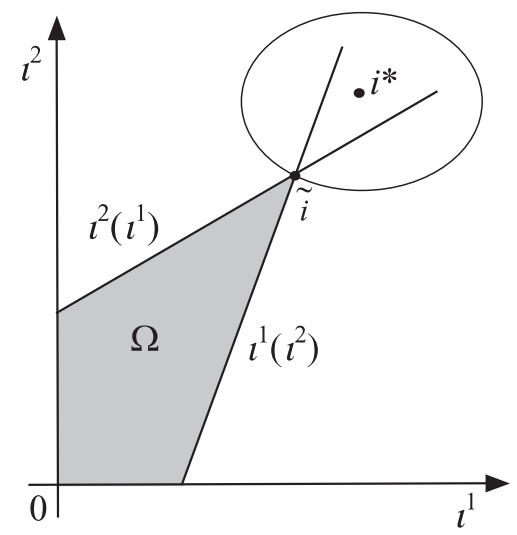


$\Omega \equiv\left\{i \mid \iota^{l} \leq \iota^{l}\left(\iota^{-l}\right)\right.$ for all $\left.l\right\}$. The above inequality together with the fact that the functions $l^{l}$ are nondecreasing in their arguments implies that (a) any investment equilibrium $\widehat{i}(\mathscr{C})$ under an arbitrary contract $\mathscr{C}$ is in the set $\Omega$ (i.e., $\widehat{i}(\mathscr{C}) \in \Omega \forall \mathscr{C}$ ), and (b) $\hat{i}^{l}(\mathscr{C}) \leq \widetilde{\imath}^{l} \leq \iota^{* l} \forall \mathscr{C}, l$. Hence, delegation of authority to $A$, which leads to $\tilde{i}$, is optimal.

Q.E.D.

\section{A.4 Proof of Lemma 1}

$A$ 's investment falls short of the efficient investment level if

$$
\frac{\partial \Pi^{A}\left(\widehat{d}^{A}(i, \epsilon), \widehat{t}^{A}, i, \epsilon\right)}{\partial i} \leq \frac{\partial \phi(i, \epsilon)}{\partial i}
$$

for all $i$ and $\epsilon$. For all $(i, \epsilon)$ define

$$
d^{*}(i, \epsilon) \in \arg \max _{d \in D}\left\{\pi^{P}(d, a(i, \epsilon), \epsilon)+\pi^{A}(d, a(i, \epsilon), \epsilon)\right\},
$$

where we assume that $d^{*}(i, \epsilon)$ exists for all $(i, \epsilon)$. Condition 1 implies that, for a given $\epsilon, \widehat{d}^{A}(i, \epsilon)$ and $d^{*}(i, \epsilon)$ do not vary in $i$. Note that $\gamma_{i}^{P}(a(i, \epsilon), \epsilon) \geq 0$ for all $i$ and $\epsilon$. This discussion in combination with (A11) implies that a sufficient condition for underinvestment is given by

(A13)

$$
\begin{gathered}
\beta^{P} \cdot\left\{\left[\rho^{A}\left(\widehat{d}^{A}(i, \epsilon), \epsilon\right)+\rho^{P}\left(\widehat{d}^{A}(i, \epsilon), \epsilon\right)\right]-\left[\rho^{A}\left(d^{*}(i, \epsilon), \epsilon\right)+\rho^{P}\left(d^{*}(i, \epsilon), \epsilon\right)\right]\right\} \\
\leq \rho^{P}\left(\widehat{d}^{A}(i, \epsilon), \epsilon\right)
\end{gathered}
$$

for all $i$ and $\epsilon$. The definition of $d^{*}(i, \epsilon)$ implies that the left-hand side of (A13) is nonpositive. Hence, (A13) is satisfied for all $(i, \epsilon)$, because $\rho^{P}(\widehat{d}, \epsilon) \geq 0$ by assumption.

Q.E.D.

\section{A.5 Proof of Proposition 2}

If $i^{D}<i^{*}$ (see (11)), Proposition 1 implies that unrestricted delegation of authority (i.e., $D^{*}=D$ ) is optimal. Next, consider the case $i^{D} \geq i^{*}$. Define a truncated decision space $D(\omega) \equiv\left[0, \bar{d}^{1}-\omega^{1}\right] \times \cdots \times\left[0, \bar{d}^{n}-\omega^{n}\right]$, where $\omega^{l} \in\left[0, \bar{d}^{l}\right] \forall l \in\{1, \ldots, n\}$. In analogy to (10), define

$$
\widetilde{\rho}^{A}(\epsilon, \omega) \equiv \max _{\widehat{d} \in D(\omega)}\left\{\beta^{P} \rho^{A}(\widehat{d}, \epsilon)-\beta^{A} \rho^{P}(\widehat{d}, \epsilon)\right\} .
$$

Conditions 1 and 2 ensure that solutions to (A14) exist for all $\epsilon$ and $\omega$. Condition 2 implies $\widetilde{\rho}^{A}(\epsilon, \omega) \geq 0 \forall \epsilon, \omega$. This observation together with the concavity of $E[\phi(i, \epsilon)]$ implies $E\left[\beta^{A} \cdot \phi_{i i}(i, \epsilon)+a_{i i}(i, \epsilon) \cdot \widetilde{\rho}^{A}(\epsilon, \omega)\right]<0 \forall i, \omega$. Hence, it follows from $i^{D} \geq i^{*}$ that $E\left[a_{i}\left(i^{*}, \epsilon\right) \cdot \widetilde{\rho}^{A}\left(\epsilon, \omega^{0}\right)\right] \geq E\left[\beta^{P} \cdot \phi_{i}\left(i^{*}, \epsilon\right)\right]>0$, where $\omega^{0} \equiv(0, \ldots, 0)$. Now, define $\bar{\omega} \equiv\left(\bar{d}^{1}, \ldots, \bar{d}^{n}\right)$. Condition 2 implies $\widetilde{\rho}^{A}(\epsilon, \bar{\omega})=0$, and hence $E\left[a_{i}\left(i^{*}, \epsilon\right) \cdot \widetilde{\rho}^{A}(\epsilon, \bar{\omega})\right]$ $=0$. Moreover, as $\rho^{A}$ and $\rho^{P}$ are continuous in $\widehat{d}$, it follows from Berge's theorem of the maximum that the value function $\widetilde{\rho}^{A}$ is continuous in $\omega$. Hence, the intermediatevalue theorem implies that there exists an $\omega^{*}$ such that $E\left[\beta^{A} \phi_{i}\left(i^{*}, \epsilon\right)+a_{i}\left(i^{*}, \epsilon\right)\right.$. $\left.\widetilde{\rho}^{A}\left(\epsilon, \omega^{*}\right)\right]=E\left[\phi_{i}\left(i^{*}, \epsilon\right)\right]$. Consequently, if party $A$ is free to choose from the set $D\left(\omega^{*}\right)$ ex post, he finds it optimal to invest $i=i^{*}$ ex ante.

Q.E.D. 


\section{References}

Aghion, P., AND J. TiRole [1997], “Formal and Real Authority in Organizations,” Journal of Political Economy, 105, 1-29.

- - , M. DEWATRIPONT, AND P. REY [2002], "On Partial Contracting," European Economic Review, 46, 745-753.

Armstrong, M. [1994], "Delegation and Discretion," Working Paper, Department of Economics, University College, London.

BAligA, S., AND T. SJÖSTRÖM [1998], "Decentralization and Collusion,” Journal of Economic Theory, 83, 196-232.

- - AND - - [2001], "Optimal Design of Peer Review and Self-Assessment Schemes," RAND Journal of Economics, 32, 27-51.

Bernheim, B., And M. Whinston [1998], "Incomplete Contracts and Strategic Ambiguity," American Economic Review, 88, 902-932.

Che, Y. K., AND D. Hausch [1999], "Cooperative Investments and the Value of Contracting," American Economic Review, 89, 125-147.

Edlin, A., AND B. Hermalin [2000], "Contract Renegotiation and Options in Agency Problems," Journal of Law, Economics, \& Organization, 16, 395-423.

- - AND S. REICHELSTEIN [1996], "Holdups, Standard Breach Remedies, and Optimal Investment," American Economic Review, 86, 478-501.

Grossman, S., AND O. HART [1986], "The Costs and Benefits of Ownership - A Theory of Vertical and Lateral Integration," Journal of Political Economy, 94, 691-719.

HaRT, O. [1995], Firms, Contracts, and Financial Structure, Clarendon Lectures in Economics, Clarendon Press: New York.

- - AND J. MOORE [1990], "Property Rights and the Nature of the Firm," Journal of Political Economy, 98, 1119-1158.

- - AND - - [1999], "Foundations of Incomplete Contracts," Review of Economic Studies, $66,115-138$.

HoL MSTROM, B. [1984], "On the Theory of Delegation,” pp. 115-141 in: M. Boyer and R. Kihlstrom (eds.), Bayesian Models in Economic Theory, North-Holland: New York.

- - AND J. RoBERTS [1998], “The Boundaries of the Firm Revisited," Journal of Economic Perspectives, 12, 73-94.

LAFFOnT, J.-J., AND J. TIROLE [1993], A Theory of Incentives in Procurement and Regulation, MIT Press: Cambridge, MA.

Macaulay, S. [1963], "Non-Contractual Relations in Business: A Preliminary Study," American Sociological Review, 28, 55-70.

Maskin, E., AND J. MOORE [1999], "Implementation and Renegotiation," Review of Economic Studies, 66, 39-56.

- - AND J. TIROLE [1999], “Two Remarks on the Property-Rights Literature," Review of Economic Studies, 66, 139-149.

MCAFEE, P., AND J. MCMillan [1995], “Organizational Diseconomies of Scale,” Journal of Economics and Management Strategy, 4, 399-426.

Melumad, N., AND T. ShiBAno [1991], "Communication in Settings with No Transfers," RAND Journal of Economics, 22, 173-198.

- - , D. MOOKHERJEe, AND S. ReICHELSTEIn [1992], "A Theory of Responsibility Centers," Journal of Accounting and Economics, 15, 445-484.

- - , - - , AND - - [1995], "Hierarchical Decentralization of Incentive Contracts," RAND Journal of Economics, 26, 654-672.

MoOKHERJEE, D. [2003], "Delegation and Contracting Hierarchies: An Overview," Working Paper, Department of Economics, Boston University.

- - AND S. REICHELSTEIN [1997], "Budgeting and Hierarchical Control," Journal of Accounting Research, 35, 129-155. 
- - AND - - [2001], "Incentives and Coordination in Hierarchies," Advances in Theoretical Economics, 1, 1-38.

Myerson, R. [1982], "Optimal Coordination Mechanisms in Generalized Principal-Agent Problems," Journal of Mathematical Economics, 10, 67-81.

NÖlDEKE, G., AND K. SCHMIDT [1995], "Option Contracts and Renegotiation: A Solution to the Hold-Up Problem," RAND Journal of Economics, 26, 163-179.

- - AND - - [1998], "Sequential Investments and Options to Own," RAND Journal of Economics, 29, 633-653.

PoitEVIN, M. [2000], "Can the Theory of Incentives Explain Decentralization?" Canadian Journal of Economics, 33, 878-906.

RAJAN, R., AND L. ZINGALES [1998], "Power in a Theory of the Firm," Quarterly Journal of Economics, 113, 387-432.

RoIDER, A. [2004], "Asset Ownership and Contractibility of Interaction," RAND Journal of Economics, 35, 787-802.

Schweizer, U. [2000], "An Elementary Approach to the Hold-Up Problem with Renegotiation," Bonn Econ Discussion Paper 15/2000, University of Bonn.

SEgAL, I. [1999], "Complexity and Renegotiation: A Foundation for Incomplete Contracts," Review of Economic Studies, 66, 57-82.

- - AND M. WhINSTON [2002], "The Mirrlees Approach to Mechanism Design with Renegotiation (with Applications to Hold-Up and Risk Sharing)," Econometrica, 70, 1-45.

Szalay, D. [2005], "The Economics of Extreme Options and Clear Advice," Review of Economic Studies, 72, 1173-1198.

TiRoLE, J. [1999], "Incomplete Contracts: Where Do we Stand?" Econometrica, 67, 741781.

Andreas Roider

Wirtschaftspolitische Abteilung

Universität Bonn

Adenauerallee 24-42

53113 Bonn

Germany

E-mail:

roider@uni-bonn.de 